\title{
Relative Importance of Packaging Elements of Baby Care Products in Sri Lanka: Do Demographic Factors Matter?
}

\author{
M.F.S. Faris \\ University of Kelaniya \\ K.P.L. Chandralal \\ University of Sri Jayewardenepura
}

\begin{abstract}
Baby care category has been profitable throughout the years and gained the interest of global players in Sri Lanka amidst the emergence of several local companies. Previous research on FMCG products identified that a $1 \%$ shift in packaging will result in $88.9 \%$ shift in consumer purchase intention, signifying the role of packaging in buying behavior. But there is mild research done with regards to the Baby Care Category and especially in the Sri Lankan context. This research focuses on the gap of identifying the importance of the different packaging elements of baby care products along with buyers' demographic factors. A field survey was conducted with an internet questionnaire to obtain data from a sample of Colombo residents. The results revealed that a weak positive importance was laid on "Graphics" (Color and Artwork) and on "Dimensions" (Design and Shape) of the package. The dimension of "Information" was placed relatively a higher importance in the buying decision. These findings aligned with the insights from buyers and retailers; buyers being more concerned on baby's safety prioritized ensuring product reliability. Certifications, labels, precautions, and instructions on the package guide them, which evidently is part of the dimension of Information. The results further revealed that the identified importance laid on the three dimensions of packaging elements did not significantly vary on any of the demographic
\end{abstract}


factors; gender, income, and level of education. Baby care, being a sensitive area for parents (unlike generic products), the importance placed on information was much higher due to its role played in assurance, consequently comparative lesser importance was placed on how colorful, big and stylish the packaging is, as the priority was absolute amongst buyers across diverse demographic differences.

\section{Keywords}

Baby care products; Demographic factors; Packaging elements

\section{Introduction}

The role of packaging has increased significantly due to the wide spread of selfservice retail formats and changing consumers' lifestyle in the competitive business environment (Abdullah, Kalam, \& Akterujjaman, 2013). Packaging has been identified as a vital marketing tool in converting a sale. As Silayoi and Speece (2007) claim, consumers may not think very deeply about brands at all before they go into the store to buy; also when customers have not even thought about the product much before entering the store, the intention to purchase is determined by what is communicated at the point of purchase; thus packaging plays a critical role as a communicating tool. Package elements such as quality, color, wrapper, and other characteristics have a significant impact on purchase decision (Raheem, Vishnu, \& Ahmed, 2014). For example, one study estimated that 73 percent of purchase decisions are made at the point of sale (Connolly \& Davison, 1996). Thus, its role in terms of getting customer attention, stimulating customers' perception towards a product, enhancing brand image of the product and working as an instrument for product differentiation have been widely acknowledged in literature (Rundh, 2005; Silayoi \& Speece, 2007; Underwood, 2003; Wells, Farley, \& Armstrong, 2007).

While a vast amount of research has been undertaken to examine the impact of package elements on purchase decisions of consumers, there is little research on how packaging affects purchase decisions of different product types (Aday \&Yener, 2014; Ahmad, Billoo, \& Lakhan, 2012; Alagala, Bagbi, \& Shaleye, 2018; Butkeviciene, Stravinskiene, \& Rutelioniene, 2008; Estiri, Hasangholipour, Yazdani, Nejad, \& Rayej, 2010; Hassan, Leng, \& Peng, 2012; Hussain, Ali, Ibrahim, Noreen, \& Ahmad, 2015; Kuvykaite, Dovaliene, \& Navickiene, 2009; Lajevardi, Memeshi, Fakharmanesh, Shirzadegan, \& 
Lajevardi, 2014; Raheem et al., 2014; Silayoi \& Speece, 2004, 2007; Underwood \& Klein, 2002). For example, packaging elements can be quite an important issue for low involvement products such as FMCG (Abdullah et al., 2013). For example, Silayoi and Speece (2004) found that visual package elements play a major role for products of low customer involvement. Hence, fast moving consumer goods (FMCG) manufacturers must understand consumer response to their packages and integrate the perceptual processes of the consumer into design (Nancarrow, Tiu Wright, \& Brace, 1998). Consumer insights need to be embedded in the designing process of package with an understanding of how packaging design elements get consumers to notice the package and how consumers evaluate packaging design and label: for effectiveness in the communication effort (Silayoi \& Speece, 2007).

It is more important to understand that not all consumers evaluate packaging the same way; this is also true to evaluation of packaging of different products. Demographic variables and product types can have different implications regarding the impact of packaging on purchase decisions. For instance, though research has identified the impact of packaging on buyers' decisions, the extent of influence is volatile between products and cultures. For example, citing Rundh (2009) and Ruto (2015, p. 4), it is highlighted that a product's package is becoming a volatile concept for every market player due to internationalization and globalization trends. The role played by different elements of package may also be different for different product types and categories. For example, packaging elements can be a quite an important issue for low involvement products than high involvement products (Abdullah et al., 2013; Silayoi \& Speece, 2004). There are studies done with regards to packaging and its impacts on consumer buying decisions generally, but a very few have concentrated on different product categories, for example see (Da Cruz, De AF Faria, \& Van Dender, 2007; Estiri et al., 2010; Ladipo \& Rahim, 2013). Furthermore, whether consumer behaviour is consistent across cultures is a highly debatable research issue as it could provide important insights for product and communication adoption strategies. Many cross-cultural researchers assert that knowledge developed in one culture should be confirmed before using that in new cultural contexts (Malhotra, Agarwal, \& Peterson, 1996cited in Silayoi and Speece, 2007).Most industry players believe that consumers worldwide are likely to have a similar response to many FMCG products despite cultural differences and some believe that many basic issues are likely to be similar across cultures; however it was also observed that specific details such as response to particular 
colors or themes may be interpreted differently in different cultures (Silayoi \& Speece, 2007; Walle, 1997). Similarly, demographic variables have been found to have an influence on buying decisions (Alooma \& Lawan, 2013; Chatterjee, 2013; Creusen, 2010; Majid, Said, \& Daud, 2017; Mueller et al., 2011; Roslow, Li, \& Nicholls, 2000; Sabbir Rahman, 2012; Viaene, 1997).However, there is little research on how such variables affect the perception of package elements, for example see (Ogba \& Johnson, 2010). Hence, more research on these issues is needed, as there is only limited empirical research on consumer response to packaging of different product categories, and very little of it is in Asian markets.

This study examined consumer evaluation of different elements of packaging of baby care products in the context of Sri Lanka. Baby care sector, having a different purchase dynamic and being a very sensitive area of thorough concern, different from FMCG, is scant in literature in respect of its packaging elements. Packaging has been playing multiple roles, obviously being a tool of customer attention grabber and purchase converter; thus, the important question arises on what component of the packaging of the product really impacts the consumer's behavior, in relation to baby care products, particularly among Sri Lankan customers. Sri Lanka's collectivistic culture where people display behavioral traits such as being supportive, caring, and relationship oriented, parents' assessment of relative importance of package elements such as graphics, shape $\&$ size and information of baby care products may be different from other cultures, which requires more scholarly investigations. In addition, further research is needed to examine whether parents' evaluation of relative importance of different packaging elements differ based on demographic differences of them. Therefore, purpose of this study is twofold: (a) examining the perceived relative importance of packaging elements when buying baby care products by Sri Lankan buyers and (b) investigating whether the importance placed in the packaging elements differ based on demographic differences of buyers in Sri Lanka.

\section{Literature Review}

\section{Role of Packaging}

Scholars acknowledge that many customer decisions are unplanned and made at the point of purchase (Bucklin \& Lattin, 1991; Hausman, 2000; Kollat \& Willett, 1967; Prone, 1993; Rundh, 2005). According to Connolly and Davidson (1996), around 73 percent of purchase decisions are made at the point 
of sale, highlighting the role of consumer conversion at the point of purchase. Adding to this, Otterbring, Shams, Wästlund, and Gustafsson(2013) insisted that the ability to communicate a clear and salient message on a package at the point of purchase is central. There the pack design acts as a "salesman on the shelf" (Pilditch, 1972, as cited in Rettie and Brewer, 2000).Point of purchase decisions heighten the potential for product packaging to communicate information to consumers and influence product choice (Clement, 2007; Wang, 2013), as at the point of purchase, the package of the product is what is majorly exposed to the buyer and so is of crucial importance. Urbany, Dickson, and Kalapurakal(1996) highlighted that most customers make their purchase decisions solely by looking at the front of the package.

Thus, from a marketing perspective, product packaging is an extrinsic cue (Chung, Pil Yu, \& Pysarchik, 2006), and consumers are firstly exposed to the products package, and afterwards experience the product (Orth \& De Marchi, 2007). Product packaging is therefore a means for the manufacturer to communicate subliminally with the consumer for product evaluation (Chung et al., 2006; Thalhammer, 2007). Moreover, research suggested that in the current competitive world where companies are concerned on attracting new customers, retaining existing customers and expanding the market amidst competitive pressures, to achieve their objective, one method that companies apply is stylish packaging of high quality (Ranjbarian, 1999 cited in Karimi, Mahdieh, \& Rahmani, 2013). Attractive product packaging also indicates a favorable product (DeBono, Leavitt, \& Backus, 2003).

Packaging is defined as all products made of any material of any nature to be used for the containment, protection, handling, delivery, and presentation of goods, from the raw materials to processed goods, from the producer to the user or consumer (Prendergast, 1995). Product packaging includes any container or package in which the product is marketed for sale or by which necessary information about the product is transmitted to consumers (Karimi et al., 2013). The role of packaging is shifting from that of protector to information provider and persuader (Agariya, Johari, Sharma, Chandraul, \& Singh, 2012). Initially, the function of a package was to protect products for logistics purpose whereas it is now widely used as a marketing tool, as package appeals consumer's attentiveness towards a certain brand, increases its image, and stimulates consumer's perceptions about the product (Kotler \& Armstrong, 2010; Rundh, 2005). Through identifying brands, conveying information with respect to price, 
quantity, and quality, and providing information regarding ingredients and directions, product packaging now plays an important role in product promotion (Agariya et al., 2012). As stated by Keller (2009), packaging is considered to be the less expensive tool and an effective tool in marketing communications. Butkeviciene et al. (2008) asserts that packaging has become the last and an important tool which can transfer the information to the consumer, strengthen the positioning of a product in the consumer's mind and also influence his/her process of decision making, especially at the point of purchase. When customers face with a range of products to choose from the shelf, what will attract and appeal to the consumer at the point of sale is a challenge today and packaging plays a vital role. Particularly, when manufacturers reach a stalemate on consumer satisfaction where the parity becomes smaller and smaller, the package comes in as the final and most valued tool in determining consumer purchase decision (Rundh, 2009; Shah, Ahmed, \& Ahmad, 2013). Thus, management recognition has been growing regarding the capacity of packaging to create differentiation and provide an identity for relatively homogenous consumer nondurables(Spethmann, 1994; Underwood, 1999; Underwood, Klein, \& Burke, 2001).

\section{Package Elements}

A package consists of different types of elements that are essential for grabbing and sustaining customers' attention (Otterbring et al., 2013). Package designing should be an informed decision based on consumer insights about how different elements of package affect customer responses (Silayoi \& Speece, 2007). There are many different schemes for the classification of elements of the package in scientific literature (Agariya et al., 2012). For example, packaging elements are distinguished between visual elements (i.e. color, image, size, and form) and informational elements (i.e. product attributes) (Silayoi \& Speece, 2004). In a similar way, a different classification contrasted non-verbal elements (e.g. color, size, image, graphic, material, and odor) with verbal elements (e.g. product name and user manual) (Butkevičienè, et al., 2008). According to Smith and Taylor (2004), there are six variables that must be taken into consideration by producer and designers when creating an efficient package: form, size, colour, graphics, material, and flavor. Kotler (2009) distinguishes six elements that must be evaluated when employing packaging decisions: size, form, material, colour, text, and brand. Vila and Ampuero (2007) classified elements of package to two blocks: graphic elements (color, typography, shapes used, and images) and structural elements (form, size of the 
containers, and materials). However, these classifications do not include verbal elements of package(Agariya et al., 2012). Ruto (2015) presented three dimensions namely, Package Graphics, Package Dimension, and Package Information. These elements play a variety of functions such as assisting for category identification and brand identification, highlighting brand claims and communicating product or promotional information (Garber Jr, Hyatt, \& Boya, 2008).

\section{Graphics of Packaging (Color and Art)}

Previous studies state that an important role of graphics of packaging is that they gain the attention of the consumer (Silayoi \& Speece, 2004). Graphics on the packaging makes a brand unique, preserves its individuality, helps in emphasizing brand name and stands out on the shelf (Smith \& Taylor, 2004 cited in Adam \& Ali, 2014). Silayoi \& Speece(2007) indicated that Graphics include image layout, color combinations, typography, and product photography, and the total presentation communicates an image. Ruto (2015) summarized these aspects under two, namely 'color and artwork'.

The initial attractiveness of a package is derived from the aspect of the colour of the package. Color is a basic aspect of human perception and has intrigued many researchers to study its impact and cognition on behaviour(Mehta \& Zhu, 2009). The packaging color of a product has a high intensity to elicit purchase behaviour in a consumer (Mutsikiwa \& Marumbwa, 2013). Particularly, branding is a story narrated by colour, not just in the creation of visual attractiveness, but in communicating the essence of the product including the perceived quality (Ampuero \& Vila, 2006; Ruto, 2015). Evaluation of product attributes is of less importance in low involvement decisions, so graphics and color become critical (Karimi et al., 2013; Priluck Grossman \& Wisenblit, 1999). Consumers also learn color associations, which lead them to prefer certain colors for various product categories (Priluck Grossman \&Wisenblit, 1999; Silayoi \& Speece, 2004). In addition to a package's colour, an important graphical element is the 'art' embedded in the package. Hence the art/ painting has been used in packaging by marketers to convey its influence into products (Ruto 2015). Art (a component of Graphics) has become a trend in the market due to its appeal, which was to a large extentdue to providing a sense of luxury (Hagtvedt \& Patrick, 2008). As such, art infusion has become important in packaging, regardless of the content of the piece of art itself (Hagtvedt \& Patrick, 2008; Ruto, 2015). 


\section{Dimensions of Packaging (Shape and Size)}

The shape of the package has been a decisive element at the point of sale to outstand among the product clutter. Not only the shape affects how the products are displayed or stacked on the shelf, but also influences the buyer to go for the product or not. It was also identified that for consumers who look for good deals, the size of the package provides an impression to the consumer on value for money (Karimi, et al., 2013; Prendergast \& Marr, 1997). As simply, when there are two products of the same size but one has a larger package, the buyer usually picks the larger package perceiving that there is a larger quantity/larger product, hence a greater value for the money spent (Ruto, 2015). In addition, this could imply that when product quality is hard to determine, as with generics, the packaging size effect is stronger (Silayoi \& Speece, 2004). Rochchi and Stefani (2006) asserts that the consumer feels that a larger shape of the package contains more; the consumer when encountered with two products of equal quality and price, would pick the bigger packaged product as he/she perceives a greater value from it. Thus, Rochchi and Stefani (2006) indicated the shape of the package being very important when designing a product's package to influence consumer preference. It has been identified in previous studies also that when product quality is hard to determine, the packaging size effect is stronger (Silayoi \& Speece, 2004, 2007), as such, the role of this element may depend on the product type.

\section{Information Element of Packaging}

Previous studies suggest that textual elements have a large impact on consumers' choices (Otterbring et al., 2013; Pieters \& Wedel, 2004), and there is a significant relationship between consumer purchase decision and the information on packaging (Adam \& Ali, 2014; Karimi et al., 2013). In certain products, customers tend to read the message on the label more often to ensure quality, even though graphics and shape may affect their attention at the beginning (Karimi et al., 2013; Silayoi \& Speece, 2004). Particularly when buying high involved products, consumers tend to look at product information and make decisions accordingly and the product information could change their attitude of buying the product (Adam \& Ali, 2014; Silayoi \& Speece, 2004). Written information on the package can assist consumers in making their decisions carefully as they consider product characteristics (Silayoi \& Speece, 2004). Previous research found that product information influences the 
perception of quality and preference (Dimara \& Skuras, 2003; Dransfield, Zamora, \& Bayle, 1998; Wang, 2013).

For a message to have an effect, it must be believed. Thus, it is important to ensure that the information displayed on the package or label is true and relevant, so that the consumer feels a sense of trustworthiness in the overall presentation of the product (Rocchi \& Stefani, 2006; Sevilla, 2012). According to Ruto (2015), the information selected to appear on a package should be done carefully to ensure that a positivity lingers in a consumer's mind. It is crucial in the current time that information about a product is present on the package, and as such to serve the dual role of communicating product benefits and detriments in equal measure. Countries such as America has viewed this with vigor and package information must disclose even warning signs so that the consumer is fully aware of the product attributes (Miller, 2009 cited in Ruto, 2015). It is also observed that the closer the proximity of the message is to the consumer, the more believable it is, resulting in a more effective medium of communication. Other promotional tools and even advertisements have been identified as mediums that displayed a sense of distance with the consumer, in contrary to the communication on the package, where the closer the communication medium is brought to the consumer, the more it is accepted and believed. This insight should guide marketers to place content carefully on a product's package to effectively draw the consumer closer to the product (Ruto, 2015; Sevilla, 2012).

Previous research has signaled that packaging elements have different influencing power on product preferences and purchase decisions (Kuvykaite et al., 2009). According to Silayoiand Speece (2004), visual package elements play a major role for products of low involvement and when customers are rushed to buy. Kuvykaite et al.(2009) also claim that visual elements of a package have a stronger effect on consumers when they are in the level of low involvement, in contrast to those of high involvement level, but verbal elements of package have stronger effect on those consumers who are in the level of high involvement. Kuvykaite, et al.(2009) revealed that verbal elements are more important than visual ones when consumers purchase milk and washing powder products. However, scholars further suggest that influence of package elements in buying decisions may also vary according to buyers' individual characteristics (Bloch, 1995; Kuvykaite, et al., 2009; Silayoi \& Speece, 2007). For example, Kuvykaite, et al.(2009) found that visual elements are more important for women than men and package size is more considered by buyers under 25 years old. Similarly, the study revealed that the importance of different package 
elements vary among buyers of different age groups with reference to different product types, for example, for buyers belonging to 46-60 years, the product brand is more important when buying milk; color, material and graphics are more important when buying washing powder (Kuvykaite et al., 2009). However, the availability of studies that focused on different product categories and that which examined the role of demographic factors is very limited in the literature which is needed to be broadened with more investigations.

With this background, following research questions were addressed in the present study.

1. Is perceived importance of different packaging elements different when buying baby care products by customers in Sri Lanka?

2. Whether the importance placed in the packaging elements of baby care products differ based on demographic differences of customers in Sri Lanka?

Accordingly, following three hypotheses were derived to test the research question 2.

H1: Perceived importance placed in the packaging elements of baby care products differ between male and female customers in Sri Lanka.

$\mathrm{H} 2$ : Perceived importance placed in the packaging elements of baby care products differ across different age groups of customers in Sri Lanka.

H3: Perceived importance placed in the packaging elements of baby care products differ across different educational levels of customers in Sri Lanka.

\section{Methodology}

A field survey was conducted to gather empirical data for the study. Population relevant for this study was the individuals in Sri Lanka who buy baby care products. The geographical scope of the study was limited to Colombo District due to the respondents' high exposure to a numerous number of baby care brands. The responses were obtained through a structured questionnaire which was administered through internet forms. The sample of the study consisted of 200 respondents who were obtained through convenience sampling, and data was collected in December 2016. 
Three elements of packaging namely 'graphics', 'dimensions' and 'information' were used in the study identified through the literature (Holmes \& Paswan, 2012; Jafari, Salehi, \& Zahmatkesh, 2013; Karimi, et al., 2013; Priluck Grossman \& Wisenblit, 1999; Ruto, 2015; Silayoi \& Speece, 2004). Accordingly, respondents were asked to evaluate a total of 23 statements related to the three elements of the packaging drawn from Ruto (2015): 11 statements for graphics element, 6 statements for dimension element and 6 statements for information element. All the items were rated on a five-point Likert scale ranging from 1- 'strongly disagree' to 5- 'strongly agree'. Basic demographic details of the respondents were also gathered such as age, gender and educational level with a purpose of using them for the analysis. The first research question was examined by employing descriptive measures (mean and standard deviation) and the three hypotheses related to the second research question were tested performing Independent Sample T test and ANOVA.

Goodness of measures was inspected in terms of internal consistency, unidimensionality, convergent validity and discriminant validity. Internal consistency was tested using Cronbach's Alpha on the measurement for the three dimensions, and the values obtained for 'Graphic', 'Dimension' and 'Information' were 0.954, 0.919 and 0.860 respectively. Exploratory Factor Analysis was performed to test the unidimensionality of the measures and Table 1 illustrates that items were loaded to the underlying three elements of packaging as expected which explained $65.25 \%$ of total variance.

\section{Table 1: Exploratory Factor Analysis}

$\begin{array}{lll}1 & 2 & 3\end{array}$

Cl01 I buy baby care products of which the

0.849

colour of the package is attractive.

Cl02 I buy baby care products that come $\quad 0.817$

with light coloured packages.

Cl03 Warm coloured baby care product

packages (red, orange, yellow) appeal to

me. 
Cl04 The package colour matters when I 0.863 am buying baby care products.

Cl05 I prefer a baby care package that is $\quad 0.804$ see-through.

AR01 Artwork (painting/drawing) on the package appeals to me when I buy baby care products.

AR02 Artwork communicates the elegance of the baby care products that I buy.

AR03 I buy baby care products of which the artwork of the package is attractive.

AR04 A package with beautiful artwork communicates a baby care product of high value.

AR05 Artwork on a package should relate to the baby care product in the package.

AR06 A baby care product package with structured symmetrical shapes communicates higher value.

SH01 I buy a baby care product because the shape of the package is attractive.

SH02 A package shape that is decorative appeals to me when I buy baby care products.

SH03 The package shape is an indicator of the value of the baby care product.

SH04 I feel that a package with a shape that appears large has a higher quantity of the baby care product inside it. 
SH05The more interesting the shape of the 0.863 package of the baby care product is, the more likely I am to purchase it.

SH06 I prefer a baby care product whose 0.836 package shape appears complete

IN01 I will buy a baby care product if the label on the package is clear.

IN02 Product information on the package of the baby care product is important to me.

IN04 When I buy baby care products, an attractive label on the package of the baby care product appeals to me.

IN05 A label can assist me to determine the quality of the baby care product in the package.

IN06 A label whose information tells more about the product appeals to me when I buy a baby care product.

Table 2 provides a summary of the validity test and accordingly, KaiserMeyer-Olkin Measure of Sampling Adequacy (KMO) values for all the three elements were above 0.5 , and Bartlett's Test of Sphericity was significant for all the three elements. Furthermore, Average Variance Extracted (AVE) figures were above the threshold level (0.5) and Composite Reliability (CR) values were greater than 0.7 , indicating the validity of the three measures.

Table 2: Summary of the Validity Test

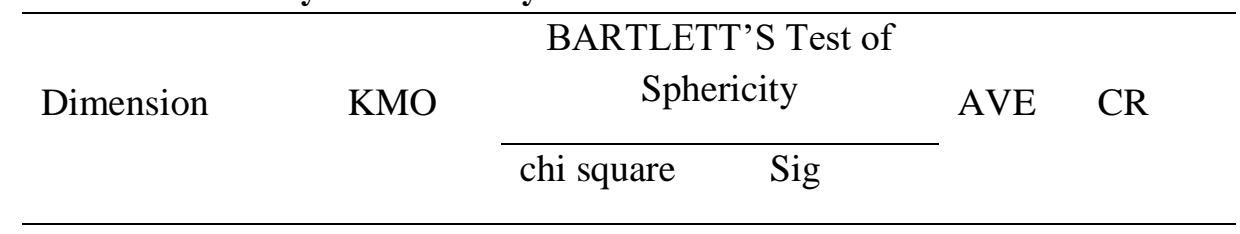




\begin{tabular}{llllll}
\hline Graphics & 0.921 & 2054.050 & 0.000 & 0.688 & 0.909 \\
Dimensions & 0.853 & 947.739 & 0.000 & 0.714 & 0.862 \\
Information & 0.701 & 728.945 & 0.000 & 0.653 & 0.797 \\
\hline
\end{tabular}

\section{Sample Profile}

Table 3 shows the sample profile of the study. The sample is slightly biased towards Females (57\%), the majority of buyers are aged 20-29 depicting Generation $\mathrm{Y}$ and Generation $\mathrm{Z}$ buyers and all respondents have children equal to or less than 3 numbers.

Table 3: Sample Profile of the Study

\begin{tabular}{llll}
\hline \multicolumn{1}{c}{ Factor } & \multicolumn{1}{c}{ Classification } & Sample & $\%$ \\
\hline Gender & Male & 87 & $43 \%$ \\
& Female & 113 & $57 \%$ \\
\hline Age & $<20$ & 0 & $0 \%$ \\
& $20-29$ & 155 & $77.5 \%$ \\
& $30-39$ & 45 & $22.5 \%$ \\
& $39<$ & 0 & $0 \%$ \\
\hline Marital Status & Married & 200 & $100 \%$ \\
& Unmarried & 0 & $0 \%$ \\
& Widowed & 0 & $0 \%$ \\
\hline No of Children & 0 & 0 & $0 \%$ \\
& $1-3$ & 200 & $100 \%$ \\
& $4-6$ & 0 & $0 \%$ \\
& 7 and above & 0 & $0 \%$ \\
\hline Monthly Income & $<20,000$ & 11 & $5.5 \%$ \\
& $20,000-39,999$ & 32 & $16 \%$
\end{tabular}




\begin{tabular}{llll} 
& $40,000-59,999$ & 47 & $23.5 \%$ \\
& $60,000-79,999$ & 27 & $13.5 \%$ \\
& $79,999<$ & 83 & $41.5 \%$ \\
\hline Level of & Ordinary Levels & 21 & $10.5 \%$ \\
& Advanced Levels & 34 & $17 \%$ \\
& Undergraduate Studies & 105 & $52.5 \%$ \\
& Postgraduate Studies & 40 & $20 \%$ \\
\hline
\end{tabular}

Most (41.5\%) in the sample had a monthly income of Rs. 80,000 and above, whereas $5.5 \%$ of the sample had a monthly income of less than Rs. 20,000. Majority of the respondents (52.5\%) had completed their Undergraduate studies.

\section{Results}

Table 4 illustrates the mean ratings of the three packaging elements. All the mean values are above average albeit the most important element is information element which scored a mean of 4.2740 indicating that this is the most considered factor in baby care packaging among buyers in Sri Lanka. Next, 'Graphics' had been rated with a 3.3045 mean value whereas the least important aspect among the three elements is the 'Dimensions' having a mean of 3.1800. This reflects that buyers still do consider Graphics and Dimensions in the package, but the severity of consideration is a lot less in comparison to Information in the package. Among 'Graphics' and 'Dimensions' aspects, Graphics (color and artwork) of the package is considered marginally more important than 'Dimensions' (shape and size).

Table 4: Mean Rating of all Dimensions of Packing

\begin{tabular}{llll}
\hline & $\begin{array}{l}\text { Mean } \\
\text { (Graphics) }\end{array}$ & $\begin{array}{l}\text { Mean } \\
\text { (Dimensions) }\end{array}$ & $\begin{array}{l}\text { Mean } \\
\text { (Information) }\end{array}$ \\
\hline Mean & 3.3045 & 3.1800 & 4.2740 \\
Std. Deviation & 0.87609 & 0.76757 & 0.46907 \\
\hline
\end{tabular}


Hypothesis 1 of the study was tested performing independent sample $t$ test to examine whether the variations observed in the importance placed on each of these three packaging elements by gender groups of males and females are significant and the results related to the evaluation of package elements between male and female respondents are shown in Table 5.

Table 5: Importance Placed on Packaging Elements by Male and Female Respondents

\begin{tabular}{llll}
\hline & Graphics & Dimensions & Information \\
\hline Male & 3.3312 & 3.2433 & 4.2460 \\
Female & 3.2840 & 3.1313 & 4.2956 \\
Total & 3.3045 & 3.1800 & 4.2740 \\
\hline
\end{tabular}

Independent sample $\mathrm{t}$ test results revealed that equal variances were observed from the Levene's test and it was identified that there was no significant difference in variances on the importance placed on all the three elements (graphics, dimensions and information) between males and females (information: $p$-value of $0.460>0.05$; graphics: p-value of $0.706>0.05$; dimensions: p-value of $0.307>0.05$ ). The results indicate that there is no significant difference in perceived importance among the three elements of packaging of baby care products between male and female customers.

Hypothesis 2 was tested performing ANOVA for each element of packaging to examine whether observations vary significantly among buyers of different income levels and Table 6 presents the evaluation of package elements by customers belonging to each income category.

Table 6: Importance Placed on Package Dimensions by Respondents of Different Income Categories

\begin{tabular}{llll}
\hline & Graphics & Dimensions & Information \\
\hline$<20001$ & 3.0331 & 2.8636 & 4.2909 \\
$20001-40000$ & 3.2983 & 3.3073 & 4.1437 \\
$40001-60000$ & 3.4139 & 3.2482 & 4.2170 \\
$60001-80000$ & 3.3704 & 3.2469 & 4.2593 \\
\hline
\end{tabular}


A STUDY ON THE RELATIVE IMPORTANCE OF PACKAGING ELEMENTS OF BABY CARE PRODUCTS

IN SRI LANKA: DO DEMOGRAPHIC FACTORS MATTER?

\begin{tabular}{llll}
\hline$>80000$ & 3.2596 & 3.1124 & 4.3590 \\
Total & 3.3045 & 3.1800 & 4.2740 \\
\hline
\end{tabular}

On 'Information', the Levene's test concluded that there is no significant variance among the groups on the importance placed on Information and no significant differences were observed (p-value of $0.205>0.05$ ). Similar results were found on graphics and dimensions showing that no significant variances were observed among customers of different income categories i.e. graphics: pvalue of $0.710>0.05$; dimensions: $p$-value of $0.413>0.05$ ). Hence, the results confirmed that there is no significant difference in the relative importance of packaging elements placed among buyers of baby care products of different income levels.

Another ANOVA was performed to test the hypothesis 3 and Table 7 illustrates the importance placed on the three packaging elements by the respondents belonging to different educational levels.

Table 7: Importance Placed on Packaging Elements by Respondents of Different Educational Backgrounds

\begin{tabular}{llll}
\hline & Graphics & Dimensions & Information \\
\hline Ordinary level & 3.3636 & 3.2698 & 4.2381 \\
Advanced level & 3.2540 & 3.1765 & 4.3000 \\
Undergraduate & 3.2797 & 3.1524 & 4.2838 \\
Postgraduate & 3.3818 & 3.2083 & 4.2450 \\
Total & 3.3045 & 3.1800 & 4.2740 \\
\hline
\end{tabular}

Results of the test revealed that there is no significant variance among different groups of educational levels on the importance placed on the three elements of packaging (information: $\mathrm{p}$-value of $0.936>0.05$; graphics: p-value of $0.897>0.05$; dimensions: p-value of $0.925>0.05$ ).

\section{Discussion of the Findings}

The three dimensions of packaging discussed are all considered by the buyer, as evidently each of it has its own role. Baby care dynamics are different 
from FMCG and so is the demographic differences among buyers in Sri Lanka, which was examined in the present study. Of the three elements of packaging, buyers of baby care products in Sri Lanka place the highest importance on information element regardless of the differences of their gender, income level or educational level. Despite baby care products being assumed to be a low involvement product category, Sri Lankan buyers seem to pay more attention to the information element other than visual aspects of the package possibly due to the fact that Sri Lankans place more care and precaution for the baby. Some scholars argue that consumers may view some of the FMCG purchases are not a low involvement action and it can vary from low to high level, depending on particular customer (Kuvykaite, et al., 2009; Silayoi \& Speece, 2004). Nevertheless, the insight obtained is in conformity with similar insights of previous research (Jaafar, Lalp, \& Naba, 2012; Karimi et al., 2013) which found information on the package indicates quality and value of the product, and a consumer will more likely purchase a product over the alternatives due to the informative role of package. Some other studies confirmed that overall; the importance of information element is higher over the visual elements regardless of the level of involvement of the purchase (Kuvykaite et al., 2009). Ruto (2015) also found similar results where he observed that a consumer responds positively to information that is well written and clear causing the consumer to perceive that a higher care has been given to the particular product by the producer hence assumes a greater perceived quality. Written information on the package assists consumers in making their decisions carefully (Karimi et al., 2013; Silayoi \& Speece, 2004). Thus the results suggest that 'information' on the packaging of baby care products tend to be of more consideration and perceived as more important by buyers in Sri Lanka for assurance and reliability of the product.

When it comes to 'Graphics', the research insights of Karimi et al.(2013), Priluck Grossman and Wisenblit(1999), and Silayoi and Speece (2004) depict that 'Graphics' become a very critical factor especially when the product is of a low involvement decision. In this instance, buyers, amidst demographic differences, have placed a moderate level of importance on the graphics aspect of baby care product package. It seems that buyers tend to be more rational when they buy baby care products than other low involvement purchasing situations, thus, pay more attention on the information element than graphics of the package as discussed above. Results derived for 'dimensions' element of baby care products suggest that buyers pay the least attention to this element 
when compared with information and graphics elements. However, Holmes and Paswan (2012) found that when a consumer feels that the thought put into designing the package of any particular product is done creatively, then it bears an influence on perceived quality, which was in reference to the shape of the package. The present study, however, found that buyers place a relatively low importance on the 'dimension' aspect of the package, possibly due to the diverse dynamics of this category as mentioned before. The average Sri Lankan buyer doesn't pay significant consideration on the dimensions element of package of baby care products. Hence, the insight of Holmes and Paswan (2012) seems less applicable to the baby care industry in Sri Lanka.

Results did not find any significant difference of the importance placed on the different packaging elements among buyers of different demographic characteristics - in terms of gender, income and educational level. Shekhar and Raveendran (2013) in their study observed a significant difference among males and females on packaging, whichisin contrast to the findings of this study. However, interpretations supportive to this study have been identified from researchers such as Leng (2010), where he concluded that the impact of packaging elements on consumer purchase decision is not stronger or weaker depending on the consumer's underlying characteristics, where gender and education level has been part of his research.

\section{Research Implications}

This study has focused to fill a gap by studying an area that has not been studied enough especially with reference to the Sri Lankan context. People spend a lot, care a lot and value a lot for their babies, which resulted in a mass number of products catering to the safety, convenience, and need of the baby. In such a situation, understanding the mental schema of the buyer of baby care products is highly valuable both for academic insights as well as managerial use. There are studies done with regards to packaging and its impacts, but a very few have concentrated on the baby care category, and very rare in the Sri Lankan context. Hence, this study has brought about knowledge of Sri Lankan buyers of baby care products in terms of their concentrations and considerations on packaging in order to provide important insights for marketing of baby care products. Academic studies focus on packaging as a part of the marketing mix of product, whereas the emerging importance of package has also been expressed as the fifth $\mathrm{P}$ in the marketing mix. Yet, connecting it to the baby 
segment was not visible. The insights brought in this study provide weight and communicates focus areas in a package for more effectiveness.

As identified by the insights gained, marketers who are engaging in the baby care industry in Sri Lanka should lay concerns on the following. Higher priority is placed by buyers on the information available on the package. Hence, adequate information needs to be placed, failing to, buyers would refrain from purchasing the baby care products having less information on the package. However, it should be kept in mind that respondents are not totally denying the consideration for graphics and dimensions, but only that it was not a comparatively highly dominant factor for purchase. Marketers can make a difference as research insists that over $70 \%$ of buyers make their purchase decision at the point of purchase (being aware of the significant impact of information on the package, besides the appeal of graphics and dimensions). The existence of the different packaging elements provides some sort of synergy as the package should be convincing, bringing together all its elements to appeal to the consumer's need at the point of purchase (Kotler \& Armstrong, 2010; Rundh, 2009), where this study displays that no package element is of no importance but relative importance varies across package elements with a comparison with previous literature supporting for and against the findings of this study. It is evident that findings differ based on cultural differences, which is where the deviations of the findings of this study fall in providing novel knowledge for further research.

\section{Limitations and Further Research}

Even though important insights were gained from the study, there are plenty of spaces to be filled in the subject. In this study, data was collected from respondents only in the vicinity of Colombo district, hence it is not identically representative of all baby care product buyers throughout Sri Lanka. Adding to this, the sample was 200. A wider research with a larger sample throughout the island needs to be undertaken to gain a more generalizable knowledge. Inherent limitations of questionnaires would have affected this study, and the need to engage in multiple modes such as focus group discussions and ethnographic research is important, at least in smaller scales throughout the island. In the study, other variables of significant impact such as country of origin, brand, distribution, and availability were not included in the study. Hence, the inclusion of those variables has the potential for deriving different insights. Thus, the insights from the study are concluded assuming the non-influence of 
the said other factors. Furthermore, the baby care product category discussed was limited to diapers, wipes, teethers, bottles, and nipples; thus, insights from the study might not be totally applicable to all baby care products.

\section{References}

Abdullah, M., Kalam, A., \& Akterujjaman, S. (2013). Packaging factors determining consumer buying decision. International Journal of Humanities and Management Sciences (IJHMS) Volume, 1.

Adam, M. A., \& Ali, K. (2014). Impact of visual packaging elements of packaged milk on consumers buying behavior. Interdisciplinary Journal of Contemporary Research in Business, 5(11).

Aday, M. S., \& Yener, U. (2014). Understanding the buying behaviour of young consumers regarding packaging attributes and labels. International Journal of Consumer Studies, 38(4), 385-393.

Agariya, A. K., Johari, A., Sharma, H. K., Chandraul, U. N., \& Singh, D. (2012). The role of packaging in brand communication. International Journal of Scientific \& Engineering Research, 3(2), 1-13.

Ahmad, N., Billoo, M., \& Lakhan, A. A. (2012). Effect of product packaging in consumer buying decision. Journal of Business Strategies, 6(2), 1-10.

Alagala, M., Bagbi, B., \& Shaleye, A. (2018). Impact of pharmaceutical packaging on consumer buying behaviour of otc drugs in port harcourt, Nigeria.

Alooma, A., \& Lawan, L. A. (2013). Effects of consumer demographic variables on clothes buying behaviour in Borno State, Nigeria. International Journal of basic and applied science, 1(4), 791-799.

Ampuero, O., \& Vila, N. (2006). Consumer perceptions of product packaging. Journal of Consumer Marketing, 23(2), 100-112.

Bloch, P. H. (1995). Seeking the ideal form: Product design and consumer response. Journal of Marketing, 59(3), 16-29.

Bucklin, R. E., \& Lattin, J. M. (1991). A two-state model of purchase incidence and brand choice. Marketing Science, 10(1), 24-39.

Butkevičienè, V., Stravinskienè, J., \& Rūtelionienè, A. (2008). Impact of consumer package communication on consumer decision making process. Engineering Economics, 56(1). 
Chatterjee, S. (2013). A study of demographic variables affecting consumer buying behaviour with reference to synthetic detergents. Indian Journal of Marketing, 43(5), 58-63.

Chung, J.-E., Pil Yu, J., \& Thorndike Pysarchik, D. (2006). Cue utilization to assess food product quality: a comparison of consumers and retailers in India. International Review of Retail, Distribution and Consumer Research, 16(02), 199-214.

Clement, J. (2007). Visual influence on in-store buying decisions: an eye-track experiment on the visual influence of packaging design. Journal of marketing management, 23(9-10), 917-928.

Connolly, A., \& Davison, L. (1996). How does design affect decision at point of sale? Journal of Brand Management, 4(2), 100-107.

Creusen, M. E. (2010). The importance of product aspects in choice: the influence of demographic characteristics. Journal of Consumer Marketing, 27(1), 26-34.

Da Cruz, A. G., De AF Faria, J., \& Van Dender, A. G. (2007). Packaging system and probiotic dairy foods. Food research international, 40(8), 951956.

DeBono, K. G., Leavitt, A., \& Backus, J. (2003). Product packaging and product evaluation: An individual difference approach 1. Journal of Applied Social Psychology, 33(3), 513-521.

Dimara, E., \& Skuras, D. (2003). Consumer evaluations of product certification, geographic association and traceability in Greece. european Journal of Marketing, 37(5/6), 690-705.

Dransfield, E., Zamora, F., \& Bayle, M.-C. (1998). Consumer selection of steaks as influenced by information and price index. Food Quality and Preference, 9(5), 321-326.

Estiri, M., Hasangholipour, T., Yazdani, H., Nejad, H., \& Rayej, H. (2010). Food products consumer behaviors: the role of packaging elements. Journal of applied sciences, 10(7), 535-543.

Garber Jr, L. L., Hyatt, E. M., \& Boya, Ü. Ö. (2008). Does visual package clutter obscure the communicabilty of food package shape? Journal of Food Products Marketing, 14(4), 21-32.

Hagtvedt, H., \& Patrick, V. M. (2008). Art infusion: The influence of visual art on the perception and evaluation of consumer products. Journal of marketing research, 45(3), 379-389.

Hassan, S. H., Leng, L. W., \& Peng, W. W. (2012). The Influence of Food Product Packaging Attributes in Purchase Decision: A Study Among 
Consumers in Penang, Malaysia. Journal of Agribusiness Marketing, Vol. 5, December 2012, p. 14-28.

Hausman, A. (2000). A multi-method investigation of consumer motivations in impulse buying behavior. Journal of Consumer Marketing, 17(5), 403-426.

Holmes, G. R., \& Paswan, A. (2012). Consumer reaction to new package design. Journal of product \& brand management, 21(2), 109-116.

Hussain, S., Ali, S., Ibrahim, M., Noreen, A., \& Ahmad, S. (2015). Impact of Product Packaging on Consumer Perception and Purchase Intention. Journal of Marketing and Consumer Research, 10(2011), 1-10.

Jaafar, S. N., Lalp, P. E., \& Naba, M. M. (2012). Consumers' perceptions, attitudes and purchase intention towards private label food products in Malaysia. Asian Journal of Business and Management Sciences, 2(8), $73-$ 90.

Jafari, S., Salehi, M., \& Zahmatkesh, R. (2013). Influence of package on consumer behavior. Oman Chapter of Arabian Journal of Business and Management Review, 34(975), 1-7.

Karimi, P., Mahdieh, O., \& Rahmani, M. (2013). The study of relationship between packaging elements and purchase behavior: Consumers of food, cosmetics and health products. Interdisciplinary Journal of Contemporary Research in Business, 5(3), 281-295.

Keller, K. L. (2009). Building strong brands in a modern marketing communications environment. Journal of marketing communications, 15(23), 139-155.

Kollat, D. T., \& Willett, R. P. (1967). Customer impulse purchasing behavior. Journal of marketing research, 4(1), 21-31.

Kotler, P. (2009). Marketing management: A south Asian perspective: Pearson Education India.

Kotler, P., \& Armstrong, G. (2010). Principles of marketing: Pearson education.

Kuvykaite, R., Dovaliene, A., \& Navickiene, L. (2009). Impact of package elements on consumer's purchase decision. Economics and management(14), 441-447.

Ladipo, P., \& Rahim, A. (2013). Packaging and the incidence of information overload in a low-risk market: A study of grocery products.

Lajevardi, M., Memeshi, E. G., Fakharmanesh, S., Shirzadegan, A., \& Lajevardi, M. (2014). Investigating the effect of packaging on consumers buyer behavior. Advances in Environmental Biology, 474-493.

Leng, L. (2010). The Influence of Packaging Attributes on Consumer's Purchase Decision of Packaged Food. 
Majid, R., Said, R., \& Daud, M. N. (2017). The impact of buyers' demography on property purchasing. Journal of Surveying, Construction and Property, $3(2)$.

Malhotra, N. K., Agarwal, J., \& Peterson, M. (1996). Methodological issues in cross-cultural marketing research: A state-of-the-art review. International marketing review, 13(5), 7-43.

Mehta, R., \& Zhu, R. J. (2009). Blue or red? Exploring the effect of color on cognitive task performances. Science, 323(5918), 1226-1229.

Mueller, A., Claes, L., Mitchell, J. E., Faber, R. J., Fischer, J., \& de Zwaan, M. (2011). Does compulsive buying differ between male and female students? Personality and Individual Differences, 50(8), 1309-1312.

Mutsikiwa, M., \& Marumbwa, J. (2013). The impact of aesthetics package design elements on consumer purchase decisions: a case of locally produced dairy products in Southern Zimbabwe. IOSR J. Bus. Manag, 8, 64-71.

Nancarrow, C., Tiu Wright, L., \& Brace, I. (1998). Gaining competitive advantage from packaging and labelling in marketing communications. British Food Journal, 100(2), 110-118.

Orth, U. R., \& De Marchi, R. (2007). Understanding the relationships between functional, symbolic, and experiential brand beliefs, product experiential attributes, and product schema: advertising-trial interactions revisited. Journal of Marketing Theory and Practice, 15(3), 219-233.

Otterbring, T., Shams, P., Wästlund, E., \& Gustafsson, A. (2013). Left isn't always right: placement of pictorial and textual package elements. British Food Journal, 115(8), 1211-1225.

Pieters, R., \& Wedel, M. (2004). Attention capture and transfer in advertising: Brand, pictorial, and text-size effects. Journal of Marketing, 68(2), 36-50.

Prendergast, G. P. (1995). The EC directive on packaging and packaging waste: current status and logistical implications. Logistics Information Management, 8(3), 10-17.

Prendergast, G. P., \& Marr, N. E. (1997). Generic products: who buys them and how do they perform relative to each other? european Journal of Marketing, 31(2), 94-109.

Priluck Grossman, R., \& Wisenblit, J. Z. (1999). What we know about consumers' color choices. Journal of marketing practice: Applied marketing science, 5(3), 78-88.

Prone, M. (1993). Package design has stronger ROI potential than many believe. Marketing News, 27(21), 13-13. 
Raheem, A. R., Vishnu, P., \& Ahmed, A. M. (2014). Impact of product packaging on consumer's buying behavior. European journal of scientific research, 122(2), 125-134.

Rettie, R., \& Brewer, C. (2000). The verbal and visual components of package design. Journal of product \& brand management, 9(1), 56-70.

Rocchi, B., \& Stefani, G. (2006). Consumers' perception of wine packaging: a case study. International Journal of Wine Marketing, 18(1), 33-44.

Roslow, S., Li, T., \& Nicholls, J. (2000). Impact of situational variables and demographic attributes in two seasons on purchase behaviour. european Journal of Marketing, 34(9/10), 1167-1180.

Rundh, B. (2005). The multi-faceted dimension of packaging: marketing logistic or marketing tool? British Food Journal, 107(9), 670-684.

Rundh, B. (2009). Packaging design: creating competitive advantage with product packaging. British Food Journal, 111(9), 988-1002.

Ruto, W. C. (2015). The Effect of Product Packaging on Consumer Choice of Cosmetic Brands: A Case of Students in USIU-Africa. United States International University-Africa.

Sabbir Rahman, M. (2012). Dynamics of consumers' perception, demographic characteristics and consumers' behavior towards selection of a restaurant: an exploratory study on Dhaka city consumers. Business Strategy Series, 13(2), 75-88.

Sevilla, J. (2012). When It's What's Outside That Matters: Recent Findings on Product and Packaging Design. ACR North American Advances.

Shah, S., Ahmed, A., \& Ahmad, N. (2013). Role of packaging in consumer buying behavior. International Review of Basic and Applied Sciences, 1(2), 35-41.

Shekhar, S. K., \& Raveendran, P. (2013). Role of packaging cues on consumer buying behaviour. International Journal of Engineering and Management Sciences, 4(1), 61-69.

Silayoi, P., \& Speece, M. (2004). Packaging and purchase decisions: An exploratory study on the impact of involvement level and time pressure. British Food Journal, 106(8), 607-628.

Silayoi, P., \& Speece, M. (2007). The importance of packaging attributes: a conjoint analysis approach. european Journal of Marketing, 41(11/12), 1495-1517.

Smith, P. R., \& Taylor, J. (2004). Marketing communications: an integrated approach: Kogan Page Publishers. 
Spethmann, B. (1994). The Mystique of the Brand: Jarred. Bagged, Boxed, Canned.

ST Wang, E. (2013). The influence of visual packaging design on perceived food product quality, value, and brand preference. International Journal of Retail \& Distribution Management, 41(10), 805-816.

Thalhammer, R. R. (2007). Natural product packaging: reflecting a contemporary philosophy. Global Cosmetic Industry, 175(12), 52-55.

Underwood, R. L. (1999). Construction of brand identity through packaging: A qualitative inquiry. Paper presented at the American Marketing Association. Conference Proceedings.

Underwood, R. L. (2003). The communicative power of product packaging: creating brand identity via lived and mediated experience. Journal of Marketing Theory and Practice, 11(1), 62-76.

Underwood, R. L., \& Klein, N. M. (2002). Packaging as brand communication: effects of product pictures on consumer responses to the package and brand. Journal of Marketing Theory and Practice, 10(4), 58-68.

Underwood, R. L., Klein, N. M., \& Burke, R. R. (2001). Packaging communication: attentional effects of product imagery. Journal of product \& brand management, 10(7), 403-422.

Urbany, J. E., Dickson, P. R., \& Kalapurakal, R. (1996). Price search in the retail grocery market. Journal of Marketing, 60(2), 91-104.

Viaene, J. (1997). Consumer behaviour towards light products in Belgium. British Food Journal, 99(3), 105-113.

Vila, N., \& Ampuero, O. (2007). The role of packaging in positioning an orange juice. Journal of Food Products Marketing, 13(3), 21-48.

Walle, A. (1997). Global behaviour, unique responses: consumption within cultural frameworks. Management Decision, 35(10), 700-708.

Wang, E. (2013). The influence of visual packaging design on perceived food product quality, value, and brand preference. International Journal of Retail \& Distribution Management, 41(10), 805-816.

Wells, L. E., Farley, H., \& Armstrong, G. A. (2007). The importance of packaging design for own-label food brands. International Journal of Retail \& Distribution Management, 35(9), 677-690. 